Amsterdam Expeditions to the West Indian Islands, Report 42*

\title{
HARPACTICOID COPEPODS FROM THE WEST INDIAN ISLANDS: CANUELLIDAE AND LONGIPEDIIDAE (COPEPODA, HARPACTICOIDA)
}

\author{
by \\ FRANK FIERS \\ Koninklijk Belgisch Instituut voor Natuurwetenschappen, Recent Invertebrates Section, Vautierstraat 29, \\ B-1040 Brussels, Belgium
}

\begin{abstract}
SUMMARY
This paper is the first of a series dealing with the systematics of harpacticoid copepods collected during the West Indian Expeditions of the University of Amsterdam. In the present paper a new species, Scottolana antillensis $\mathbf{n}$. sp., is described. Furthermore, Ellucana secunda Coull, 1971 , is compared with $E$. longicauda Sewell, 1940, and morphological details are given for Longipedia spec.
\end{abstract}

\section{RÉSUMÉ}

Cet article est le premier d'une série concernant les Copépodes Harpacticoïdes collectés pendant les Expéditions de l'Université d'Amsterdam aux Indes Occidentales. Une nouvelle espèce, Scottolana antillensis n. sp., est décrite. De plus, Ellucana secunda Coull, 1971, est comparée avec $E$. longicauda Sewell, 1940, et quelques détails morphologiques de Longipedia spec. sont donnés.

\section{INTRODUCTION}

An interesting collection of harpacticoid copepods, gathered during several expeditions to the West Indian Islands, was placed at my disposal by Prof. J. H. Stock (Amsterdam). Harpacticoids were collected in more than sixty stations distributed all over the entire study area. The collections contain species from almost all harpacticoid families.

This first report deals with three species of Harpacticoidea of the suborder Polyarthra. Scottolana antillensis $\mathbf{n}$. sp. is fully described and Ellucana secunda Coull, 1971, is compared with E. longicauda Sewell, 1940, already redescribed by Fiers (1982) and Fiers (in press). Mor-

\footnotetext{
- Report 41 is published in the same issue of this journal.
}

phological details are given for Longipedia spec., showing several differences with the actually known species of that genus.

\section{MATERIAL AND METHODS}

The material was collected in sixty stations sampled during five expeditions $(1958,1978,1979,1980$ and 1982) to the West Indian Islands. Information about these localities will be given with the description of the species.

The specimens are preserved in $75 \%$ alcohol, containing a drop of glycerine. Before dissection, the habitus was drawn and measurements were noted. The specimens were dissected and mounted in lactophenol. The figures were drawn with the aid of a camera lucida. Abbreviations used in the text and the figures are: $\mathrm{P} 1-\mathrm{P} 6=$ first to sixth leg, end = endopodite, exo = exopodite, ex = external and in = internal. The terminology is adopted from Lang (1948), while the presentation of the setal formula used in the present paper follows the method of Humes \& Ho (1969).

Type-specimens are deposited in the collections of the Zoölogisch Museum, Amsterdam.

\section{SYSTEMATICS}

Family CANUEllidae Lang, 1948

Scottolana antillensis $n$. sp.

(Figs. 1-4)

Material. - Amsterdam Expeditions to the West Indian Islands, Sta. 82-131. Jamaica: parish of Westmorland, Homers Cove $\left(18^{\circ} 13^{\prime} 13^{\sim} \mathrm{N} 78^{\circ} 16^{\prime} 54^{\sim} \mathrm{W}\right)$. Submarine spring in coarse sand, ca. $30 \mathrm{~cm}$ under the surface of the sea, and ca. $10 \mathrm{~m}$ offshore. Temperature of the spring $27.8^{\circ} \mathrm{C}$ (temperature of the seawater $29.8^{\circ} \mathrm{C}$ ). Chlorinity of the spring $31,522 \mathrm{mg} / \mathrm{l}$. March 27, 1982. One ovigerous female (holotype, dissected and mounted on three slides, labelled WIAE $2 a, b$, and $c$ ), one ovigerous female 
(paratype, undissected), one male (paratype, dissected, labelled WIAE 13a, b, and c).

Etymology. - The specific name antillensis refers to the island arc where the species was found.

\section{Description. -}

Female (holotype). Habitus (figs. 1a, b): length, including rostrum and furcal rami, 2 $\mathrm{mm}$; largest width at the level of the posterior margin of the cephalosome $230 \mu \mathrm{m}$; first to fourth thoracic segments with parallel margins; body tapering from the fifth thoracic segment towards the anal segment; cephalosome slightly concave in lateral view; pleurotergital margins of the thoracic segments straight; genital double-segment fused, showing a thick internal cuticular band, at the height of the fusion; genital double-segment slightly longer than wide; first postgenital segment (length $\times$ width) $100 \times 150 \mu \mathrm{m}$, second one $90 \times 130 \mu \mathrm{m}$ and anal segment $40 \times 110 \mu \mathrm{m}$; the integument is smooth; the hyaline fringe of each segment is unincised except for the dorsal fringe of the anal segment; the egg sacs contain each 20 eggs with an average diameter of $50 \mu \mathrm{m}$; eyespot reddish brown.

Rostrum (fig. 4g) articulating with the cephalosome; lateral margins of the rostrum tapering evenly towards the apex; apex rounded and bearing two sensorial setae.

Furcal rami (fig. 1c) short; internal margin strongly curved in the posterior half; external margin almost straight, bearing seven setae, all implanted on or nearby the distal margin; three setae implanted dorsally: a strong external one, a small and smooth proximal one and a small but feathered seta; three ventrally implanted setae: a small and smooth seta, a long one with a swollen basis and a totally rounded and thick seta; only one principal seta, implanted most apically, length $480 \mu \mathrm{m}$.

Genital area (fig. 3f) situated in the middle of the ventral side of the anterior half of the genital double-segment; composed by a symmetrical clew of integumental bands and thickenings; two blunt lateral extensions and a median one, all directed posteriorly; on both sides of the clew, a smooth seta is implanted.

Antennule identical in segmentation and setal ornamentation with the antennule of Scottolana dissimilis Fiers, 1982.

Antenna (fig. 2b): basis with a horseshoeshaped row of small teeth; endopodite threesegmented; first endopodal segment bearing two setae, second one with four setae and ultimate segment with seven setae of which one is very short and smooth; exopodite sevensegmented; first exopodal segment bearing two setae, second to sixth segment each with one seta and seventh segment bearing four, apically implanted setae; all the setae, except for the short one on the third endopodal segment and one on the first exopodal segment, remarkably ornamented.

Mandible (figs. 3d, e): gnathobasis with several rows of teeth of different shapes and with one sensorial seta; basis of coxa with two setae; endopodite two-segmented, first segment bearing three setae and second segment having nine; setae of basis of coxa and endopodal segments feathered with short setules; exopodite three-segmented with one, one and three densely feathered setae on the first to the third segment.

Maxillule (figs. 3a, b, c): separation between praecoxa, coxa and arthrite not very distinct; arthrite bearing seven armed distal spines and three setae; arthrital surface with one dorsal (fig. 3b) and two ventral (fig. 3c) setae; coxa with two densely feathered epipodal setae and four sparely feathered endital setae; basis bearing eight setae; exopodite one-segmented, rounded and having ten setae, four of them being very plumose; the most externally implanted seta is smooth and very short; endopodite two-segmented with five and six setae on the first and second segment.

Maxilla (fig. 2c): praecoxa and coxa not fused, each having two endites; setal formula of the endites (from proximal to distal) four, two, three and three; basis prolonged into a dented hook, bearing on each side a strongly armed seta; furthermore, two slender setae are implanted on the surface of the basis; endopodite 

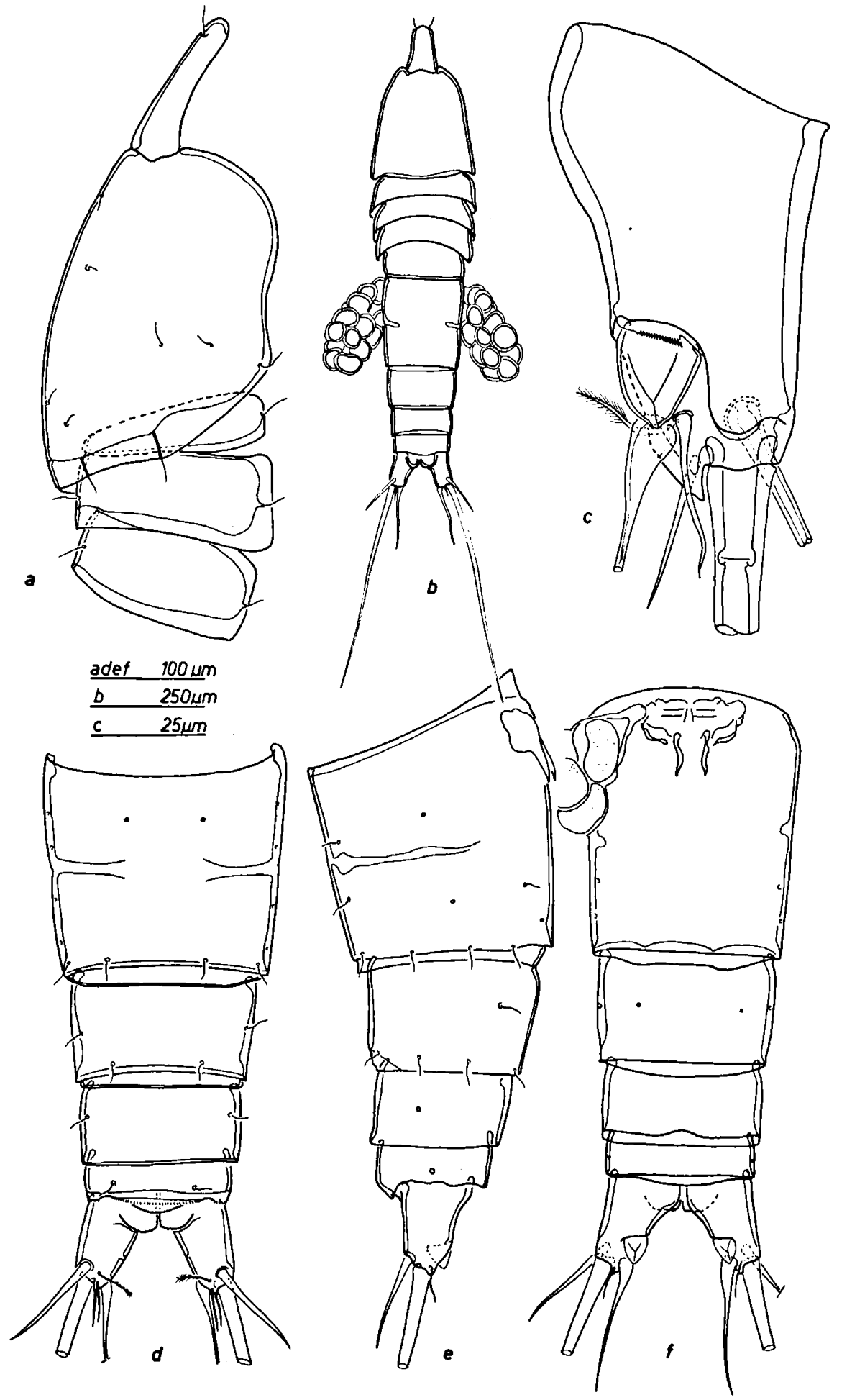

Fig. 1. Scottolana antillensis $\mathrm{n}$. sp.: a, cephalosome and thoracic segments; $b$, habitus of the female; $c$, furcal ramus in ventral view; $d$, abdomen in dorsal view; e, abdomen in lateral view; $f$, abdomen in ventral view. 


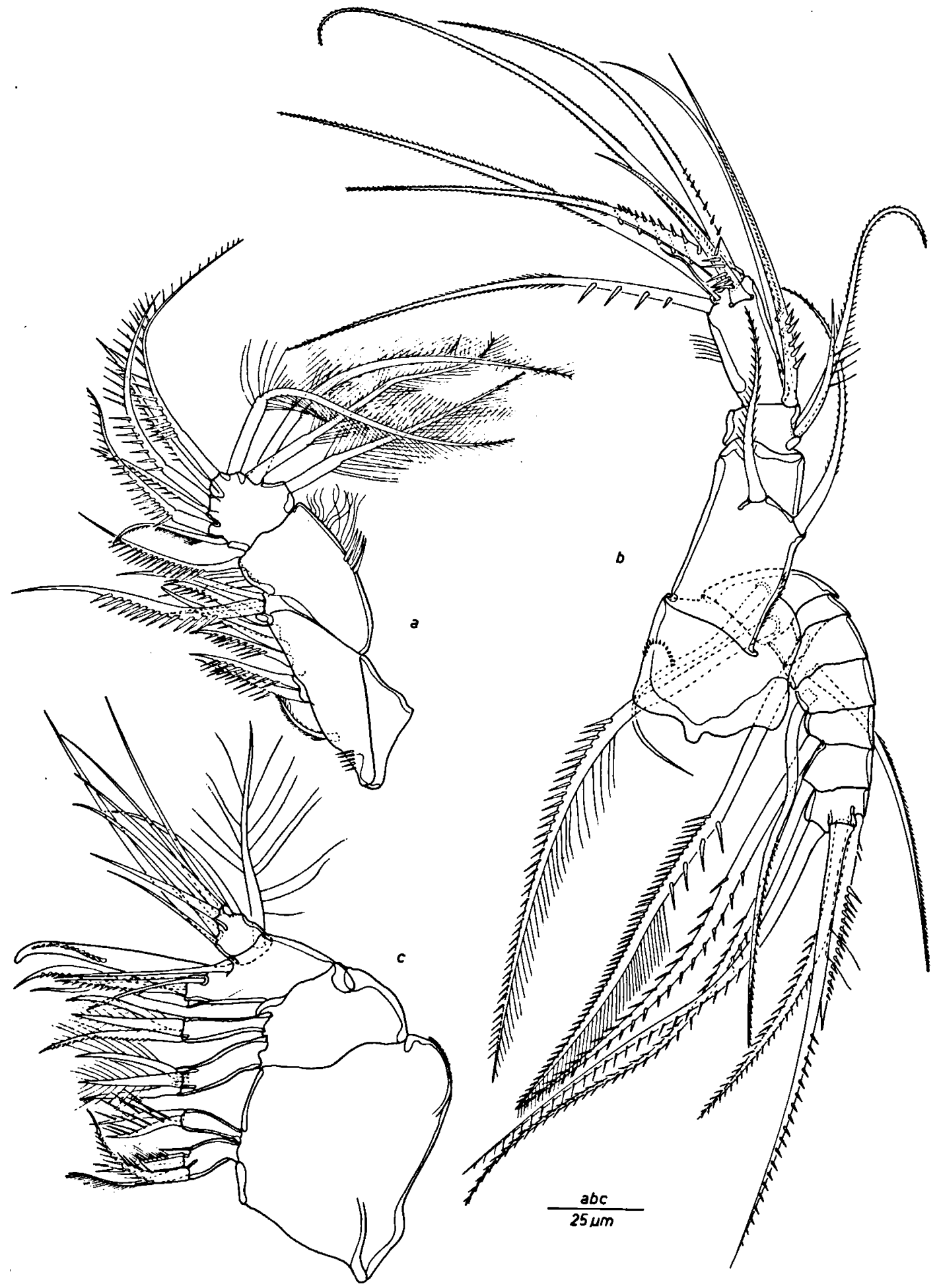

Fig. 2. Scottolana antillensis n. sp.: a, maxilliped; b, antenna; c, maxilla. 


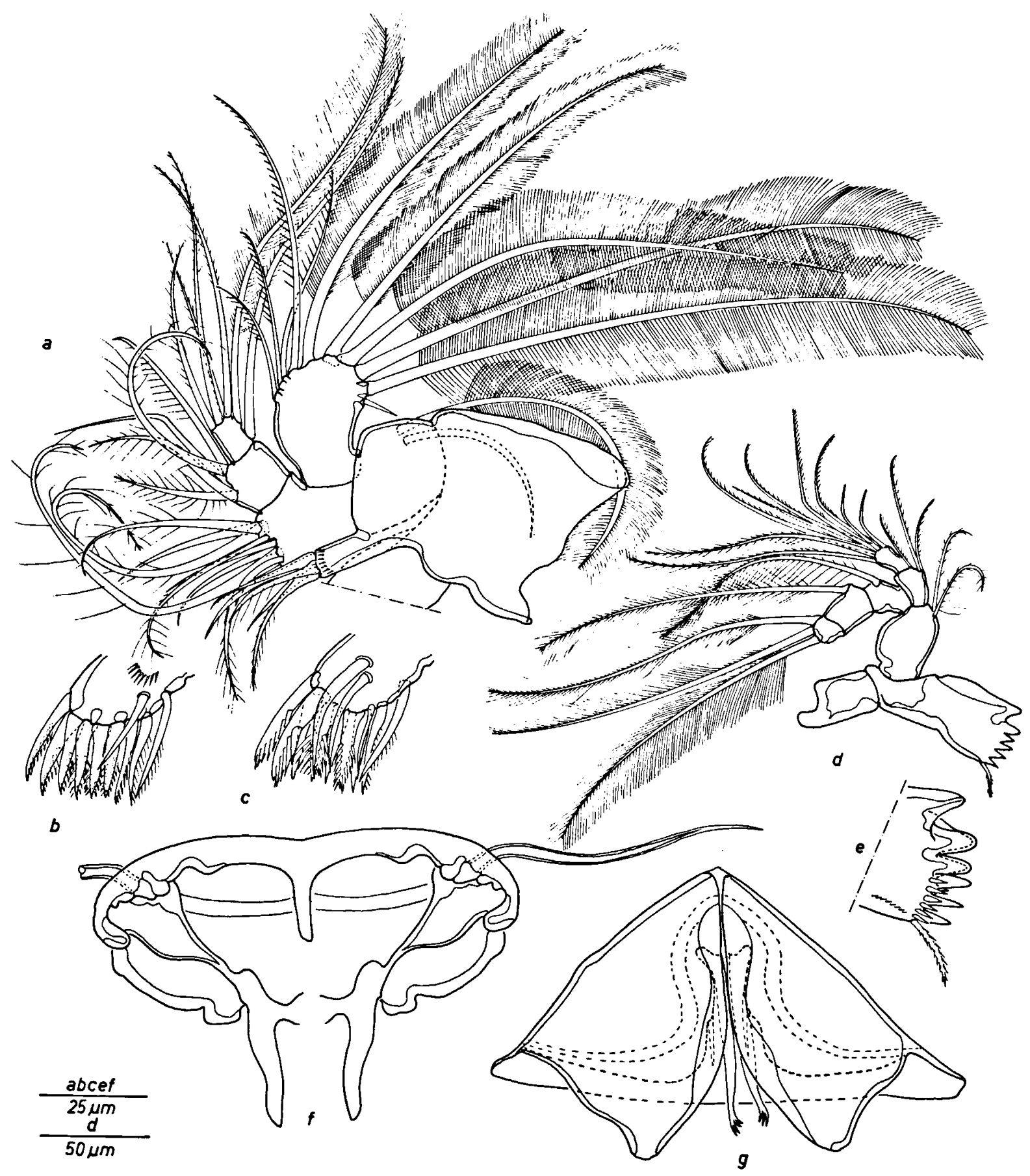

Fig. 3. Scottolana antillensis n. sp.: a, maxillula; b, arthrite in dorsal view; c, arthrite in ventral view; d, mandible; e, biting edge of the mandibular gnathobasis; $f$, genital field of the female; $g$, genital field (petasma) of the male. 


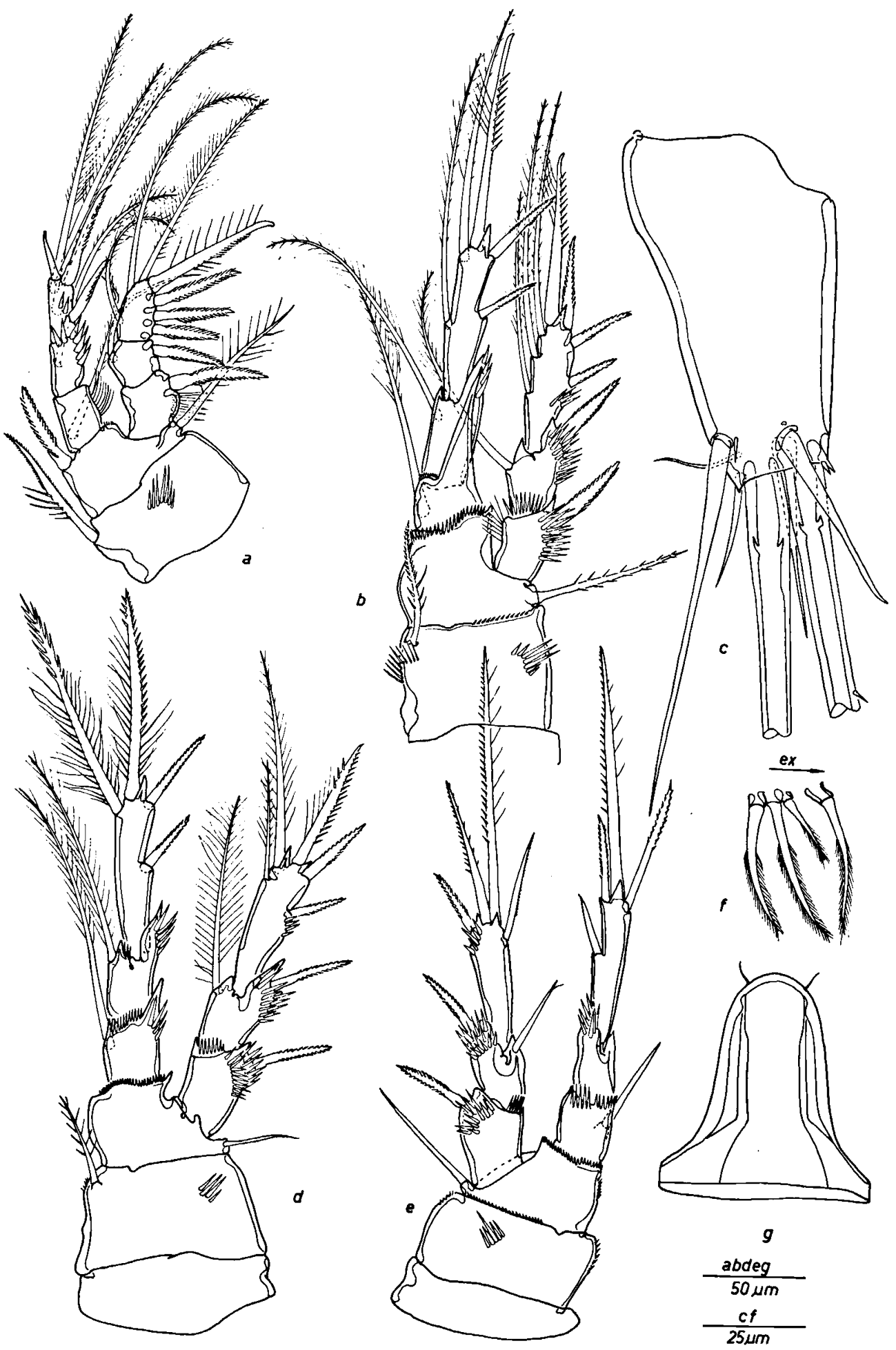

Fig. 4. Scottolana antillensis n. sp.: a, P1; b, P2; c, furcal ramus of the male in ventral view; d, P3; e, P4; f, P5; g, rostrum. 
distinct, one-segmented and having nine setae, the most proximal one with long setules.

Maxilliped (fig. 2a): praecoxa, coxa and basis not fused; praecoxa without setae; coxa with two groups of spines: proximal group composed by two, distal group by four strong setae; basis bearing six setae and having hairs and spinules along the external margin; endopodite with ten setae, four of them very densely feathered while the six internal ones show strong spinules along their stem.

P1 (fig. 4a): coxa rectangular, bearing an internal strong seta and a comb of strong teeth on the surface; basis with an internal strongly armed spine and a feathered external seta; exopodite and endopodite three-segmented.

\section{TABLE I}

Setal formula of Scottolana antillensis $\mathbf{n}$. sp.

\begin{tabular}{|c|c|c|c|c|c|}
\hline \multirow[t]{2}{*}{ P1 } & $\operatorname{coxa} 0-1$ & basis 1-I & exo I-0 & I-1 & IV-3 \\
\hline & & & end $0-1$ & $0-1$ & III-3 \\
\hline \multirow[t]{2}{*}{ P2 } & coxa $0-1$ & basis 1-0 & exo I-0 & $\mathrm{I}-0$ & IV -3 \\
\hline & & & end $0-1$ & $0-1$ & III-2 \\
\hline \multirow[t]{2}{*}{ P3 } & $\operatorname{coxa} 0-1$ & basis 1-0 & exo I-0 & $\mathrm{I}-1$ & III-2 \\
\hline & & & end $0-1$ & $0-1$ & IV \\
\hline \multirow[t]{2}{*}{ P4 } & $\operatorname{coxa} 0-0$ & basis $1-0$ & exo I-0 & $\mathrm{I}-1$ & IV \\
\hline & & & end $0-1$ & $0-0$ & IV \\
\hline
\end{tabular}

P2 (fig. 4b): coxa with two combs of teeth and an internal seta, ornamented with strong setules; basis with an external, feathered seta; exopodite and endopodite three-segmented; external margin of the exopodal segments covered with strong spinules; first endopodal segment extended into a long and sharp process; second segment also protruded but less conspicuous than the preceding segment.

P3 and P4 (figs. 4d, e): coxae with a small row of spinules; P3 with an internal seta, P4 without; basis of P3 and P4 with a smooth external seta; exopodites and endopodites with three-segmented rami; external margins of the exopodal segments covered with strong spinules; subdistal internal spine of the third endopodal segment of P3 with slender setules in the proximal two-thirds and peculiarly armed in its distal third; second segments of both en- dopodites and exopodites sharply extended in both legs.

P5 (fig. 4f) represented by four setae; external seta somewhat separated from the other setae; all setae feathered with short setules.

Male (paratype). Habitus: length $710 \mu \mathrm{m}$, proportional lengths of thoracic and abdominal segments as in the female, except for the genital segments which are separated.

Furcal rami (fig. 4c) as in the female but with two developed principal setae; internal seta 415 $\mu \mathrm{m}$, external principal seta $250 \mu \mathrm{m}$ long; setae without the modifications observed in the female; all setae smooth.

Genital field (fig. 3g) (petasma): composed of two triangular plates covering the genital entrance; one smooth and one long modified seta implanted along the margins of the genital groove.

The legs of the male without sexual dimorphism.

Discussion. -

Scottolana antillensis $\mathrm{n}$. $\mathrm{sp}$. is assigned to the genus Scottolana Por, 1964, because of the following characteristics:

- the sexual dimorphism of the inner seta of the furcal rami;

- the setal formula of the legs, especially the configuration (exo) 0-1-4 / (end) 1-0-4 of P4;

- the shape of the female and male genital area.

The species can be easily discriminated from the other species of the genus by the very thick inner seta of the furcal rami in the female, the shape of the genital field in both sexes and the peculiarly shaped distal spines of the third endopodal segment of P3.

In many respects, $S$. antillensis n. sp. resembles most $S$. bulbifera (Tscheslenko, 1971) but differs from the latter by the free first legbearing segment, the setal formula of $\mathrm{P} 4$ and the spines of the endopodite of P3.

This resemblance is most interesting because the importance of some generic characteristics, such as the individualization of the first thoracic segment and the setal formula of $\mathrm{P} 4$, is insuffi- 
ciently known. The discovery of $S$. antillensis $\mathbf{n}$. sp. probably indicates that the abovementioned characteristics appeared several times and independently in the CanuellaScottolana group.

\section{Ellucana secunda Coull, 1971}

(Figs. 5-6)

Material. - Amsterdam Expeditions to the West Indian Islands, Sta. 78-315. Curaçao: Piscadera Bay, at the first buoy, in washings of the top layer of coarse coral sand collected by SCUBA divers at a depth of $-4 \mathrm{~m}$. Estimated position: $12^{\circ} 07^{\circ} 42^{\sim} \mathrm{N} 68^{\circ} 58^{\circ} 18^{\sim} \mathrm{W}$. May 22, 1978. Three females (one of these is dissected and mounted on three slides, labelled WIAE 1a, b, and c).

\section{Remarks. -}

Coull (1971) gave a description of both male and female; our sample however, contained only female specimens. Because Ellucana longicauda Sewell (1940) was redescribed in previous papers (Fiers, 1982 and Fiers, in press), a detailed comparison of both species can be given here. As far as the habitus is concerned, $E$. secunda and $E$. longicauda resemble each other closely. $E$. secunda measures (including rostrum and furcal rami) $1.110 \mathrm{~mm}$ with the greatest width at the level of the posterior margin of the cephalothorax $(215 \mu \mathrm{m})(n=3)$. In both species the ratio of the length of the cephalothorax to the body length is $1: 5$ ( $E$. longicauda $1: 4.8$ and $E$. secunda $1: 5.2)$. The thoracic and abdominal segments taper evenly towards the anal segment. The genital segments show, on both sides, a thick internal cuticular structure. The ratio of the length to the width of the genital segments is $1: 1.0$ (in $E$. longicauda $1: 1.2$ ) (figs. $5 \mathrm{a}, \mathrm{b}, \mathrm{c})$.

The genital area resembles that of $E$. longicauda but differs from the latter in the shape of the integumental structures. The external margin of the furcal rami curves towards the anal segment. The rami measure $170 \mu \mathrm{m}$ (in $E$. longicauda $190 \mu \mathrm{m}$ ) and bear one dorsal, two lateral, two principal setae (external one 240 $\mu \mathrm{m}$ and internal one $960 \mu \mathrm{m}$ ), and a small apical seta. The posterior margin of the rami is extended ventrally to a rounded hyaline process.

The shape and the number of setae and spines of the antennule is the same in both species. The only difference is a thickened seta on the posteriorly directed margin of the ultimate segment in $E$. secunda.

The basis of the antenna bears no seta in $E$. secunda. The first endopodal segment has two setae: one slender unarmed and a strongly armed one. The left antenna of the dissected female shows an aberrant endopodite (fig. 6b). The right antenna of this specimen and both antennae of the undissected specimens show a normal endopodite. The first endopodal segment of the aberrant antenna bears only one strongly armed seta, the second and third segment are fused and have six internal setae and five apical ones.

The maxillula differs from $E$. longicauda in the length of the internal seta of the exopodal segment. In $E$. secunda this seta is much longer than the homologous structure in $E$. longicauda.

In the legs the only striking differences between both species are the protruding endopodal segments of $\mathrm{P} 2$, the setal formula of $\mathrm{P} 2$ and the shape of the setae in P4 (fig. 6a). In $E$. secunda the external spines on the first and second exopodal segments of $\mathrm{P} 4$ are remarkably long and reach beyond the distal margin of the last segment. The distal setae of the third exopodal segment of $\mathrm{P} 4$ in $E$. secunda clearly differ from $E$. longicauda: these elements are seta-like in the former and show a more spine-shaped structure in the latter.

It is beyond any doubt that Ellucana longicauda Sewell and $E$. secunda Coull are closely related species. The most important characteristics allowing discrimination between both species are the reduced setal formula of $\mathrm{P} 2$, the extended endopodal segments of P2 and the setiform spines of the exopodite of $\mathrm{P} 4$.

$E$. secunda seems to be widely distributed along the Atlantic coasts of Central America. Up to now, this species has been reported from Barbados (Coull, 1970, 1971), North Carolina (Coull, 1971) and Curaçao (this paper). Furthermore, two specimens of $E$. secunda were 

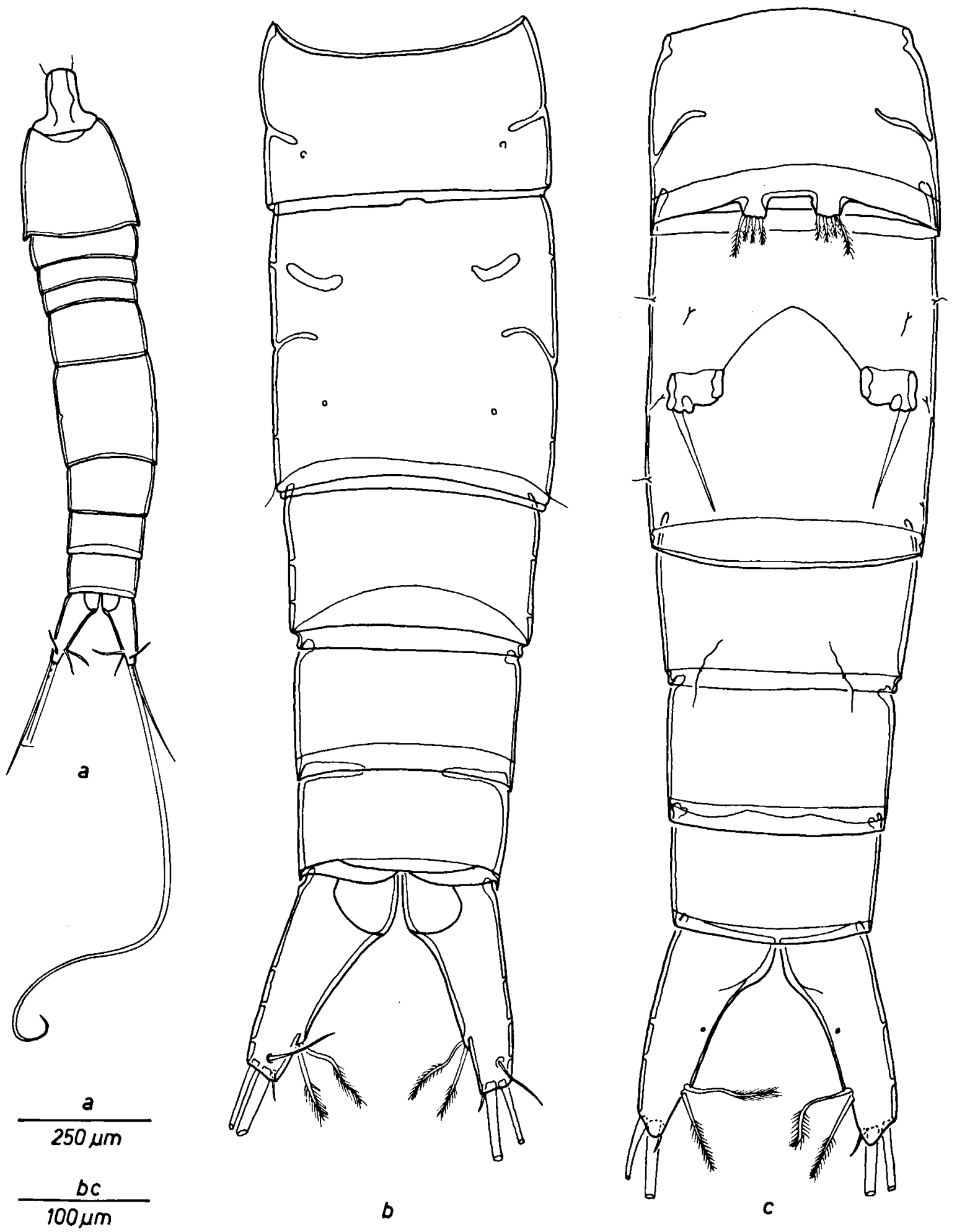

Fig. 5. Ellucana secunda Coull, 1971: a, habitus; b, abdomen in dorsal view; c, abdomen in ventral view. 


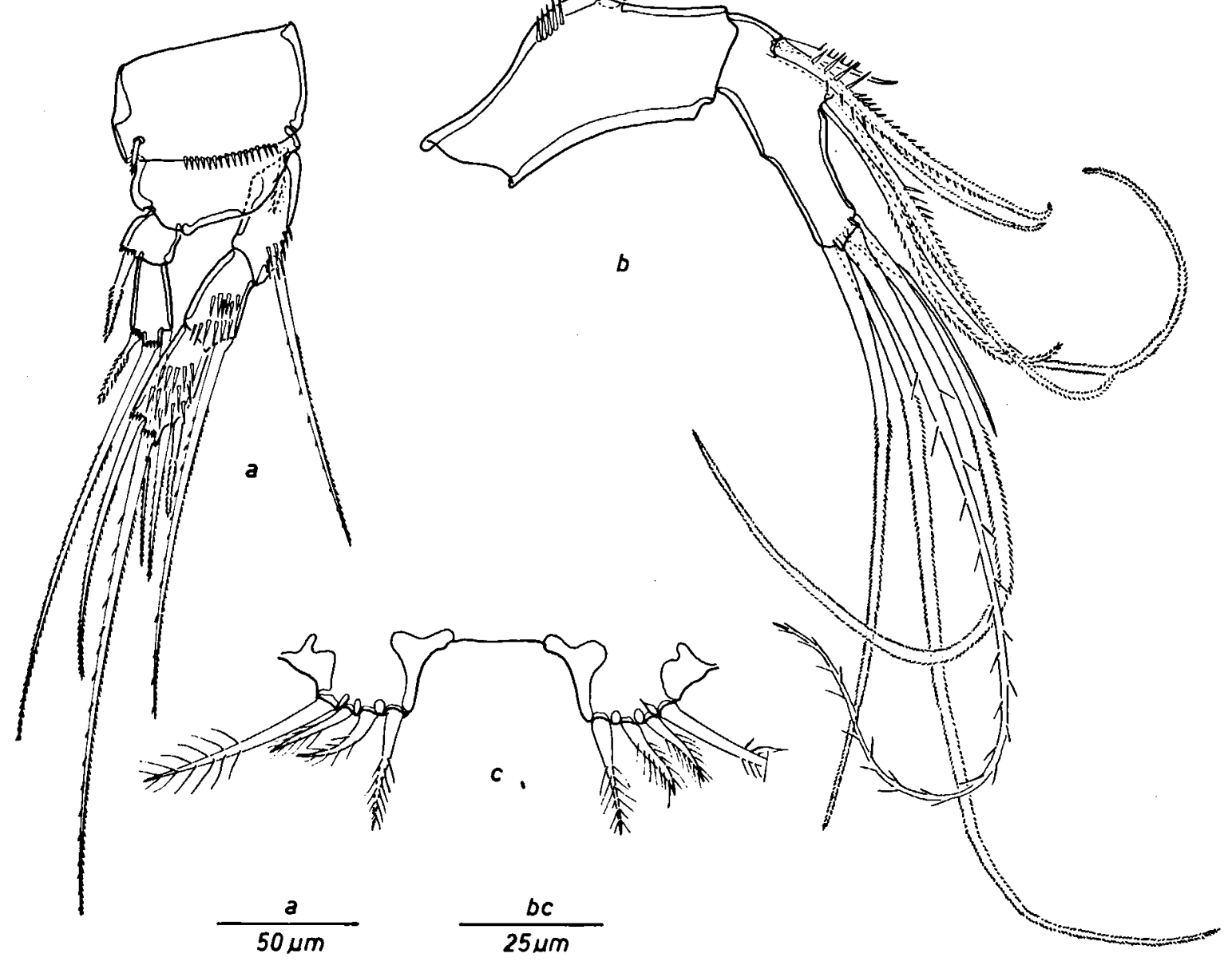

Fig. 6. Ellucana secunda Coull, 1971: a, P4; b, aberrant endopodite of female antenna; c, P5.

found in coral sand samples from Yucatan, Mexico and one specimen in a sample from Cozumel, Mexico. These specimens, collected by Dr. M. D. W. Wellens during a stay in Mexico, are deposited in the author's collection.

Family LONGIPEDIIDAE Sars, 1903

\section{Longipedia spec.}

(Figs. 7-8)

Material. - Amsterdam Expeditions to the West Indian Islands, Sta. 80-60. Bonaire: interstitial of a small beach in the lagoon called Lac at Sorobon $\left(12^{\circ} 05^{\prime} 37^{\sim} \mathrm{N}\right.$ $\left.68^{\circ} 14^{\circ} 05^{\sim} \mathrm{W}\right)$. In coarse sand with many coral fragments; temperature $30^{\circ} \mathrm{C}$. June 4,1980 . One female, dissected and mounted on five slides, labelled WIAE 12a, b, c, d, and $\mathbf{e}$.

Description. -

Length $0.920 \mathrm{~mm}$; body shape and rostrum as in $L$. coronata Claus, 1863 ; tergites with a finely denticulated hyaline fringe (fig. 8f); surface of the pleurotergites almost without integumental structures except for some spare rows of very minute spinules; abdominal segments (figs. 7a, $b, c)$ having a very fragile pattern of integumental spinules, except the first genital segment; second genital segment having two bulbose structures on its ventral surface; anal segment with a row of long spinules along the ventral 

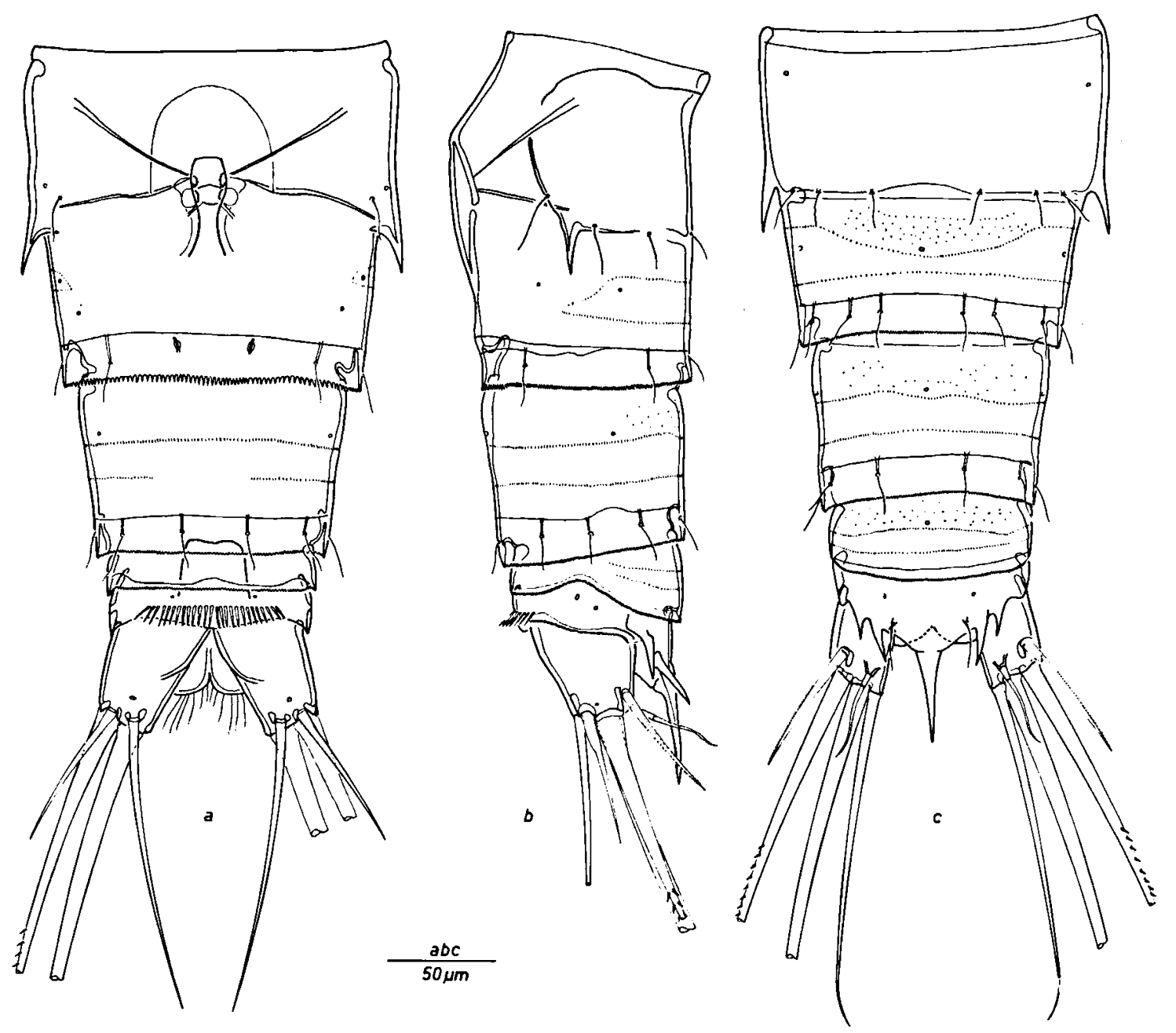

Fig. 7. Longipedia spec.: a, abdomen in ventral view; b, abdomen in lateral view; c, abdomen in dorsal view.

side; anal operculum with a median spine, flanked on each side with two small sharp spines; internal distal seta slightly longer than the ventral one; principal internal seta $750 \mu \mathrm{m}$ long, principal external one $370 \mu \mathrm{m}$, inner distal seta (dorsally implanted) $160 \mu \mathrm{m}$, inner distal seta (ventrally implanted) $150 \mu \mathrm{m}$, ventral external seta $75 \mu \mathrm{m}$ and dorsal external seta $70 \mu \mathrm{m}$ long.

P1 (fig. 8b): coxa with an externally directed row of long spinules; distal spinule much stronger than the preceding ones; several rows of minute spinules on the surface of the coxa; internal coxal seta barbed along one side, in the distal half of the stem; basis without integumen- tal structures, bearing one inner strongly armed spine and a feathered external seta; rami, setae and spines as in $L$. coronata.

P2 (fig. 8a): coxa with two rows of long spinules and two rows of small ones; coxal seta finely armed; basis without ornamentations, bearing a seta with very strong setules; first endopodal segment with a sharp brownish and curved distal hook; surface covered with small spinules and a row of long spinules; second endopodal segment with a longitudinal row of long teeth; third endopodal segment entirely covered with parallel rows of small spinules; distal endopodal spines with remarkably strong teeth. 


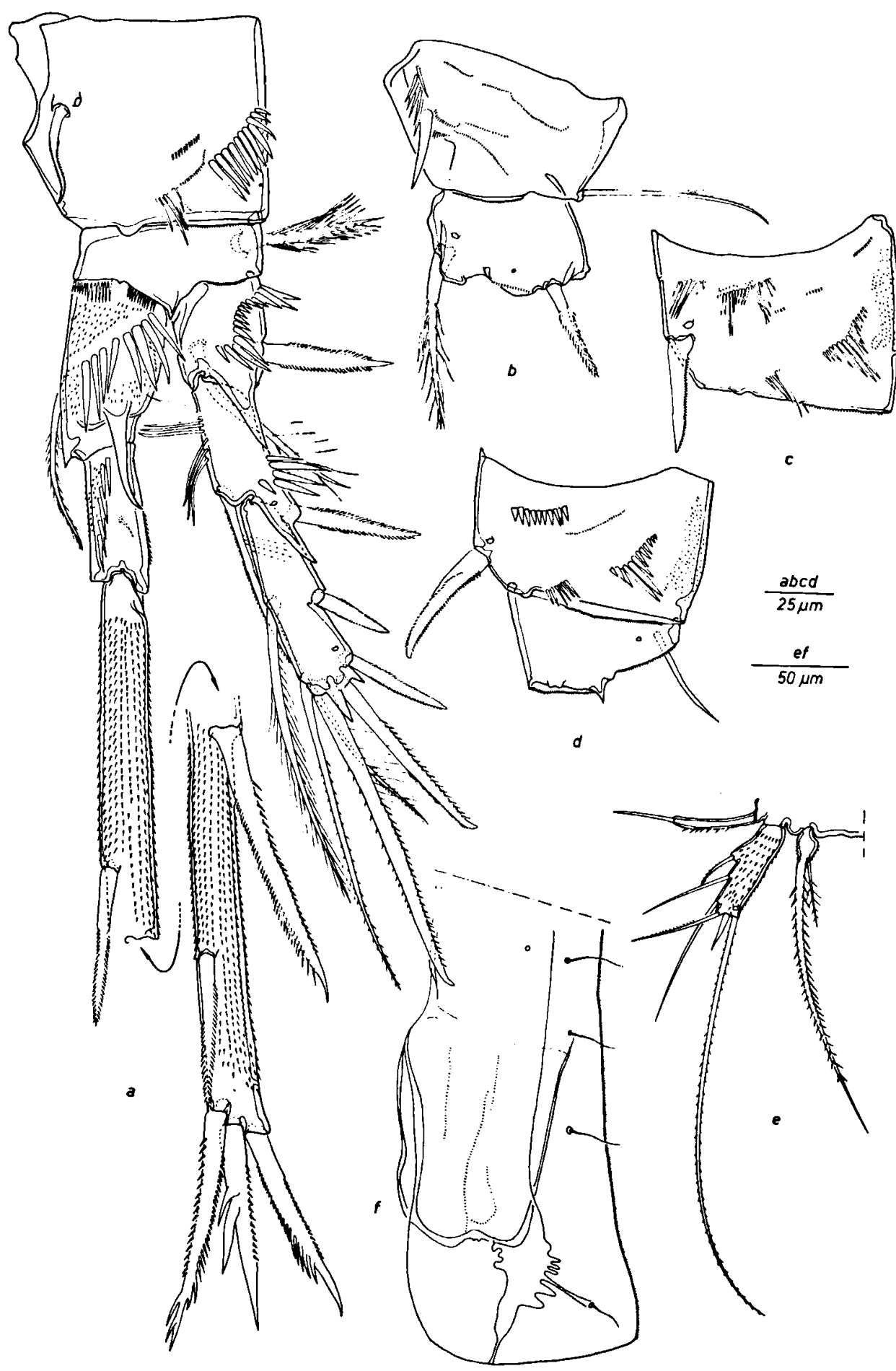

Fig. 8. Longipedia spec.: a, P2; b, coxa and basis of P1; c, coxa of P3; d, coxa and basis of P4; e, P5; f, pleurotergite of second thoracic segment. 
P3 (fig. 8c): coxa with a strong internal spine and furnished with several rows of long spinules; external margin of the coxa covered with a pattern of small spinules; first and second endopodal segments with a pattern of small spinules; setae of the second endopodal segment with proportional lengths as in $L$. kikuchii Itô, 1980.

P4 (fig. 8d): coxa with a proximal row of broad spinules, two rows of long, and one row of minute teeth; external margin covered with small spinules; internal spine of the second endopodal segment strong and armed with teeth along each side.

P5 (fig. 8e): exopodite covered with small spinules only, and bearing six setae; inner seta very long and furnished with small setules; proximal part of the baseoendopodite bulbose and having small teeth; distal part prolonged and covered with spines; baseoendopodal seta feathered.

The setal formula of the legs is identical to that of $L$. coronata.

\section{Discussion. -}

Most unfortunately, the sample studied here contained only one female. Notwithstanding critical examination of the characteristics, it is impossible to designate this specimen to any known species. In the following list some characteristics, used by Wells (1980) in his outstanding revision of the family, are briefly discussed.

- The very reduced ornamentation of the thoracic segments (as in L. americana Wells, 1980, and L. helgolandica santacruzensis Mielke, 1979, fide Wells, 1980).

- The finely incised hyaline fringe of the pleurotergites, differentiating this specimen from $L$. coronata, $L$. kikuchii, $L$. nichollsi Wells, 1980 and L. weberi Scott, 1909.

- The strong spinule at the top of the external row on the coxa of P1 (comparable with $L$. nichollsi).

- The strong and sharp process on the distal edge of the first endopodal segment of P2 (as in $L$. coronata and $L$. scotti G. O. Sars, 1903).
- The third endopodal segment of P2 is entirely covered with longitudinal rows of spinules.

- The strong, toothed distal spines of the third endopodal segment of P2 (as in L. nichollsi and in some specimens of $L$. kikuchii).

- The long exopodite of P5, covered with small spinules only.

- The inner seta of the second endopodal segment of P3 (as in L. kikuchii).

\section{ACKNOWLEDGEMENTS}

I am much indebted to Prof. Dr. J. H. Stock (Amsterdam) for the loan of this interesting material. Many thanks are due to Dr. K. Wouters (Brussels) for his good advice and for his critical review of the manuscript.

The fieldwork on which this study is based has been supported by grants of the Beijerinck-Popping Fonds (Amsterdam), the Netherlands Foundation for the Advancement of Tropical Research (WOTRO, The Hague), the Treub Maatschappij (Utrecht), the Fonds Landbouwhogeschool (Wageningen), and the Amsterdamse Universiteits Vereniging (Amsterdam).

\section{REFERENCES}

Coull, B. C., 1970. Harpacticoid copepods from Barbados and Jamaica, W.I. with description of two new species. Caribb. J. Sci., 10 (3-4): 127-133 [non vidi].

- , 1971. Meiobenthic Harpacticoida (Crustacea, Copepoda) from the North Carolina continental shelf. Cah. Biol. mar., 12: 195-237.

Fiers, F., 1982. New Canuellidae from the northern coast of Papua New Guinea (Copepoda, Harpacticoida). Bull. Inst. r. Sci. nat. Belg., 54 (4): 1-32, pls. I-XVII.

- -, in press. A new record of Ellucana longicauda Sewell, with the description of the male (Copepoda: Harpacticoida: Canuellidae). Indo-Mal. Zool.

Humes, A. G. \& Ju-Shey Ho, 1969. The genus Sunaristes (Copepoda, Harpacticoida) associated with hermit crabs in the western Indian Ocean. Crustaceana, 17 (2): 113-130.

LANG, K., 1948. Monographie der Harpacticiden, 1: 1-896 (Håkan Ohlsson, Lund).

MielKe, W., 1979. Interstitielle Fauna von Galapagos, 25. Longipediidae, Canuellidae, Ectinosomatidae (Harpacticoida). Mikrofauna Meeresbodens, 77: 1-107.

PoR, F. D., 1967. Level bottom harpacticoids (Crustacea, Copepoda) from Elat (Red Sea), 1. Israel J. Zool., 16: 101-165.

SewELl, R. B. S., 1940. Copepoda Harpacticoida. Scient. Rep. John Murray Exped., 7 (2): 117-382. 
TschesLenko, L. L., 1971. New common forms of harpacticoids (Copepoda, Harpacticoida) from Prossjet Bay of the Sea of Japan. Proc. White Sea biol. Stat., zool. Inst., 8 (16): 151-161 [in Russian].
WeLls, J. B. J., 1980. A revision of the genus Longipedia Claus (Crustacea: Copepoda: Harpacticoida). Zool. J. Linn. Soc., 70: 103-189.

Received: 9 August 1984 